\title{
Risk Factors for the Requirement of Antenatal Insulin Treatment in Gestational Diabetes Mellitus
}

\author{
Mayu Watanabe, ${ }^{1,2}$ Akihiro Katayama, ${ }^{1}$ Hidetoshi Kagawa, \\ Daisuke Ogawa, ${ }^{1,2}$ and Jun Wada ${ }^{1}$ \\ ${ }^{1}$ Department of Nephrology, Rheumatology, Endocrinology and Metabolism, Okayama University Graduate School of Medicine, \\ Dentistry and Pharmaceutical Sciences, Okayama 700-8558, Japan \\ ${ }^{2}$ Department of Internal Medicine, Japanese Red Cross Society Himeji Hospital, Himeji, Hyogo 670-8540, Japan
}

Correspondence should be addressed to Mayu Watanabe; mitahamamamaka@yahoo.co.jp

Received 21 June 2016; Revised 26 September 2016; Accepted 23 October 2016

Academic Editor: Kazuya Yamagata

Copyright (C) 2016 Mayu Watanabe et al. This is an open access article distributed under the Creative Commons Attribution License, which permits unrestricted use, distribution, and reproduction in any medium, provided the original work is properly cited.

Poor maternal glycemic control increases maternal and fetal risk for adverse outcomes, and strict management of gestational diabetes mellitus (GDM) is recommended to prevent neonatal and maternal complications. However, risk factors for the requirement of antenatal insulin treatment (AIT) are not well-investigated in the pregnant women with GDM. We enrolled 37 pregnant women with GDM and investigated the risk for AIT by comparing the patients with AIT (AIT group; $n=10$ ) and without insulin therapy (Diet group; $n=27$ ). The 1-h and 2-h plasma glucose levels and the number of abnormal values in $75 \mathrm{~g}$ OGTT were significantly higher in AIT group compared with Diet group. By logistic regression analysis, plasma glucose level at 1-h was significant predictor for AIT and the odds ratios were 1.115 (1.004-1.239) using forward selection method and 1.192 (1.006-1.413) using backward elimination method. There were no significant differences in obstetrical outcomes and neonatal complications. 1$\mathrm{h}$ plasma glucose levels in $75 \mathrm{~g}$ OGTT are useful parameters in predicting the requirement for AIT in GDM. Both maternal and neonatal complications are comparable in GDM patients with and without insulin therapy.

\section{Introduction}

International Association of Diabetes and Pregnancy Study Groups (IADPSG) published criteria for the universal screening and diagnosis for gestational diabetes mellitus (GDM) based on Hyperglycemia and Adverse Pregnancy Outcome (HAPO) study [1]. After the release, the criteria for GDM were also updated in Japan [2] and they were characterized by two major revisions. First, GDM is diagnosed if one or more of the following criteria are met in the $75 \mathrm{~g}$ oral glucose tolerance test (OGTT) and threshold values were defined as a fasting plasma glucose level of $5.1 \mathrm{mmol} / \mathrm{L}(92 \mathrm{mg} / \mathrm{dl})$, a 1h plasma glucose level of $10.0 \mathrm{mmol} / \mathrm{L}(180 \mathrm{mg} / \mathrm{dl})$, and a 2h plasma glucose level of $8.5 \mathrm{mmol} / \mathrm{L}(153 \mathrm{mg} / \mathrm{dl})$. Second, the new criteria exclude overt diabetes in pregnancy from GDM. By these new diagnostic criteria, the total incidence was $17.8 \%$ and FPG plus 1-h plasma glucose levels identified a large majority of these individuals [1].

Poor maternal glycemic control can significantly increase maternal and fetal risk for adverse outcomes [3] and strict management of GDM is recommended to prevent neonatal and maternal complications. Several studies have shown the treatment interventions, including dietary treatment, self-monitoring blood glucose levels, and insulin therapy if required, reduced prenatal complications $[4,5]$. Crowther et al. found that 20 percent of women with GDM need antenatal insulin treatment (AIT) to achieve good glycemic control [6], while other studies also showed that 10.8 52.8 percent of GDM patients required AIT [7-11]. In addition, BaptisteRoberts et al. reviewed that the AIT was the risk factor for the development of type 2 diabetes [12]. However, the risk factors for the requirement of AIT are not well-investigated and this prompted us to investigate the clinical characteristics of the patients with GDM to identify risk factors for AIT.

\section{Materials and Methods}

2.1. Subjects. The current clinical investigation is a noninterventional and retrospective study enrolling 37 pregnant women with GDM. They were diagnosed at $35.2 \pm 4.7$ years 
of age at their estimated $20.9 \pm 3.8$ gestational weeks and admitted between 2010 and 2016 at Himeji Red Cross Hospital, Hyogo, Japan. GDM was diagnosed according to IADPSG criteria [1]. Data collected included gestational age at diagnosis, gestational weeks at diagnosis, twins, family history of diabetes mellitus, pregestational body mass index (BMI), infertility treatments such as timed intercourse, in vitro fertilization, and egg donation, hospitalization for threatened premature delivery and intravenous ritodrine hydrochloride, prior gestational diabetes, primipara, plasma glucose levels of $75 \mathrm{~g}$ OGTT (fasting, 1-h, and 2-h), number of abnormal values of $75 \mathrm{~g}$ OGTT, glycosylated hemoglobin Alc (HbAlc), weeks of gestation at start of insulin therapy, the maximum of insulin dose, obstetrical outcome such as weeks of gestation at delivery, preterm delivery, cesarean section, pregnancy-induced hypertension (PIH), and neonatal characteristics such as birth weight, neonatal plasma glucose levels, hypoglycemia defined as plasma glucose levels of less than $45 \mathrm{mg} / \mathrm{dL}$, transient tachypnea of the newborn (TTN), and respiratory distress syndrome (RDS). We excluded the patients with overt diabetes in pregnancy, with known type 1 or type 2 diabetes before pregnancy, or having not undergone $75 \mathrm{~g}$ OGTT. Furthermore, pregnant women were classified as normal weight $\left(\mathrm{BMI}<25 \mathrm{~kg} / \mathrm{m}^{2}\right)$, overweight $(25 \leq \mathrm{BMI}$ $\left.<30 \mathrm{~kg} / \mathrm{m}^{2}\right)$, and obese $\left(30 \leq \mathrm{BMI} \mathrm{kg} / \mathrm{m}^{2}\right)$ according to pregestational BMI. The study protocol was approved by the institutional review boards of Himeji Red Cross Hospital.

2.2. Treatments. The patients received dietary education from registered dietitians with $30 \mathrm{kcal} / \mathrm{kg}$ weight of ideal body weight based on BMI $22 \mathrm{~kg} / \mathrm{m}^{2}$ supplemented with 200 to $250 \mathrm{kcal}$, and they were instructed to take three meals and one to three snacks. They also received instructions for the procedures to perform self-monitoring of blood glucose (SMBG) and measured daily both preprandial and 2-hour postprandial glucose levels. If targeted glucose levels with preprandial glucose less than $5.6 \mathrm{mmol} / \mathrm{L}(100 \mathrm{mg} / \mathrm{dl})$ and 2 hour postprandial glucose less than $6.7 \mathrm{mmol} / \mathrm{L}(120 \mathrm{mg} / \mathrm{dl})$ were not achieved three times or more after breakfast, lunch, and dinner during seven days, AIT was initiated before breakfast, lunch, and dinner, respectively. We classified the patients into two groups, the patients who received AIT (AIT group; $n=10$ ) and the patients without insulin therapy (Diet group; $n=27$ ).

2.3. Statistical Analysis. All data were presented as the mean \pm standard deviation. For univariate analysis, we used Student's $t$-test and $\chi$-square test for categorical data. For multivariate logistic regression analysis after controlling simultaneously for potential confounders, we selected independent variables which were significantly higher in AIT group compared with Diet group for univariate analysis, such as postprandial PG at 1-hr and 2-hr in $75 \mathrm{~g}$ OGTT and number of abnormal values in $75 \mathrm{~g}$ OGTT. We also used the forward selection and backward elimination methods. Logistic regression analyses with each independent variable to explore risk factors contributing to AIT were also performed. We performed receiver-operating characteristic (ROC) curve to identify clinical factors to predict the requirement for AIT. We determined a cut-off value by the point on the ROC curve closest to the upper left corner. $P$ values of less than 0.05 were considered statistically significant. The data were analyzed with IBM SPSS Statistics Ver. 22.0 and IBM SPSS Regression (IBM).

\section{Results}

3.1. Characteristics of GDM. Maternal age, number of twins, family history of DM, pregestational BMI, infertility treatment, prior gestational diabetes, primipara, fasting plasma glucose levels at $75 \mathrm{~g}$ OGTT, and HbAlc levels demonstrated no significant differences between AIT and Diet groups. The gestational age at diagnosis was lower in AIT group (18.9 \pm 2.0 weeks) compared with Diet group $(21.6 \pm 4.1$ weeks $)$, but it did not reveal significant differences $(P=0.053)$. The 1 -h and 2 -h plasma glucose levels and number of abnormal values in $75 \mathrm{~g}$ OGTT were significantly higher in AIT group compared with Diet group (Table 1). The maximal glucose level during ritodrine treatment in AIT group was higher compared to Diet group, the intravenous injection of ritodrine to treat preterm delivery was more frequently administered in AIT group (40.0\%) compared with Diet group (14.8\%), but it was not statistically significant (Table 1).

3.2. Risk Factors for AIT. By logistic regression analysis, plasma glucose level at 1-h was significant predictor for AIT and the odds ratios were 1.115 (1.004-1.239) using forward selection method and 1.192 (1.006-1.413) using backward elimination method (Table 2). In logistic analyses using each independent variable, plasma glucose levels at 1 -h and 2$\mathrm{h}$ and the number of abnormal values in $75 \mathrm{~g}$ OGTT were only significant predictors for AIT and the odds ratios were 1.128 (1.022-1.246), 1.054 (1.006-1.104), and 10.950 (1.95961.218), respectively (Table 3 ). ROC curves were used to determine the cut-off values of $1-h$ and $2-h$ plasma glucose levels and the number of abnormal values to predict the AIT (Figure 1). The cut-off values of 1-h and 2-hr plasma glucose levels and the number of abnormal values in $75 \mathrm{~g}$ OGTT were $10.25 \mathrm{mmol} / \mathrm{L}$ (AUC 0.872 , sensitivity $100 \%$, and specificity of $77.8 \%$ ), $8.75 \mathrm{mmol} / \mathrm{L}$ (AUC 0.756, sensitivity 70\%, specificity $70.4 \%$ ), and 1.5 (AUC 0.783 , sensitivity $80 \%$, and specificity $74.1 \%$ ), respectively (Table 4 ).

3.3. Obstetrical Outcomes and Neonatal Characteristics. The rate of cesarean section and $\mathrm{PIH}$ was higher in AIT group compared with Diet group, but it was not statistically significant (Table 5). There were no differences in the rate of preterm delivery; however, gestational age at delivery was significantly lower in AIT group $(36.4 \pm 2.0$ weeks $)$ compared with Diet group $(38.2 \pm 2.4$ weeks) (Table 5$)$. There was no stillbirth, Apgar score at 5 minutes less than 8, shoulder dystopia, and birth weight more than 4000 grams. TTN occurred more often in AIT group compared with Diet group without significant differences (Table 6). There was no difference in the rate of RDS between two groups. Birth weight, neonatal 
TABLE 1: Characteristics of GDM.

\begin{tabular}{|c|c|c|c|}
\hline & AIT group $(n=10)$ & Diet group $(n=27)$ & $P$ value \\
\hline Gestational age at diagnosis (years) & $33.8 \pm 7.0$ & $35.7 \pm 3.6$ & $0.284^{\dagger}$ \\
\hline Gestational weeks at diagnosis (weeks) & $18.9 \pm 2.0$ & $21.6 \pm 4.1$ & $0.053^{\dagger}$ \\
\hline Twins, $n(\%)$ & $2(20.0)$ & $1(3.7)$ & $0.107^{\ddagger}$ \\
\hline Family history of diabetes mellitus, $n(\%)$ & $7(70.0)$ & $16(59.3)$ & $0.550^{\ddagger}$ \\
\hline Pregestational BMI $\left(\mathrm{kg} / \mathrm{m}^{2}\right)$ & $24.5 \pm 4.8$ & $23.0 \pm 4.4$ & $0.383^{\dagger}$ \\
\hline $95 \% \mathrm{CI}$ & $21.0-27.9$ & $21.3-24.7$ & \\
\hline$<20.0(\%)$ & 20.0 & 14.8 & \\
\hline $20-24.9(\%)$ & 40.0 & 59.3 & \\
\hline $25-29.9(\%)$ & 30.0 & 18.5 & \\
\hline$\geq 30.0(\%)$ & 10.0 & 7.4 & \\
\hline Infertility treatment, $n(\%)$ & $4(40.0)$ & $12(44.4)$ & $0.809^{\ddagger}$ \\
\hline Treatment of preterm labor with ritodrine, $n(\%)$ & $4(40.0)$ & $4(14.8)$ & $0.098^{*}$ \\
\hline Maximal glucose levels during ritodrine treatment $(\mathrm{mmol} / \mathrm{L})$ & $9.0 \pm 1.2$ & $7.3 \pm 0.7$ & $0.062^{\dagger}$ \\
\hline Prior gestational diabetes, $n(\%)$ & $1(10.0)$ & $5(18.5)$ & $0.532^{\ddagger}$ \\
\hline Primipara, $n(\%)$ & $5(50.0)$ & $12(44.4)$ & $0.763^{\ddagger}$ \\
\hline \multicolumn{4}{|l|}{ Plasma glucose level (mmol/L) } \\
\hline Fasting & $4.82 \pm 0.49$ & $4.69 \pm 0.46$ & $0.465^{\dagger}$ \\
\hline At $1 \mathrm{hr}^{\S}$ & $10.86 \pm 0.62$ & $9.19 \pm 1.57$ & $0.003^{\dagger}$ \\
\hline At $2 \mathrm{hr}^{\S}$ & $9.43 \pm 1.56$ & $7.96 \pm 1.37$ & $0.008^{\dagger}$ \\
\hline Number of abnormal values, $n$ & $1.9 \pm 0.6$ & $1.26 \pm 0.4$ & $0.001^{\dagger}$ \\
\hline $\operatorname{HbAlc}(\%)$ & $5.3 \pm 0.3$ & $5.2 \pm 0.4$ & $0.234^{\dagger}$ \\
\hline Gestational weeks at start of AIT (weeks) & $26.1 \pm 5.9$ & & \\
\hline The maximum of insulin dose (units/day) & $10 \pm 5.5$ & & \\
\hline
\end{tabular}

AIT, antenatal insulin treatment; BMI, body mass index; CI, confidence interval; and HbAlc, hemoglobin Alc.

Data are shown as mean \pm SD or $n$.

${ }^{\dagger}$ By Student's $t$-test.

${ }^{*}$ By Chi-square test.

'At the time of the $75 \mathrm{~g}$ oral glucose tolerance test.

${ }^{\S}$ After the administration of $75 \mathrm{~g}$ of glucose.

TABLE 2: Logistic regression analysis after controlling simultaneously for potential confounders of predictors for antenatal insulin treatment (AIT).

\begin{tabular}{lccc}
\hline Independent variables & $\beta$-Coefficient & Odds ratio (95\% CI) & $P$ values \\
\hline Postprandial PG at 1-hr in 75 g OGTT & 0.165 & $1.179(0.988-1.407)$ & 0.067 \\
Postprandial PG at 2-hr in 75 g OGTT & 0.053 & $1.054(0.987-1.126)$ & $1.521(0.207-11.201)$ \\
Number of abnormal values in 75 g OGTT & 0.420 & & 0.113 \\
\hline Forward selection method (conditional) & & $1.115(1.004-1.239)$ & 0.680 \\
Postprandial PG at 1-hr in 75 g OGTT & 0.109 & $4.267(0.669-27.228)$ & 0.043 \\
Number of abnormal values in 75 g OGTT & 1.451 & & 0.125 \\
\hline Backward elimination method (conditional) & & $1.192(1.006-1.413)$ & 0.042 \\
Postprandial PG at 1-hr in 75 g OGTT & 0.176 & $1.061(0.998-1.127)$ & 0.057 \\
\hline Postprandial PG at 2-hr in 75 g OGTT & 0.059 &
\end{tabular}

AIT, antenatal insulin treatment; PG, plasma glucose; 75 g OGTT, $75 \mathrm{~g}$ oral glucose tolerance test, BMI, body mass index, and HbAlc, hemoglobin Alc.

TABLE 3: Logistic regression analysis with each independent variable of predictors for antenatal insulin treatment (AIT).

\begin{tabular}{lccc}
\hline & $\beta$-Coefficient & Odds ratio (95\% CI) & $P$ values \\
\hline Postprandial PG at 1-hr in 75 g OGTT & 0.121 & $1.128(1.022-1.246)$ & 0.017 \\
Postprandial PG at 2-hr in 75 g OGTT & 0.053 & $1.054(1.006-1.104)$ & 0.026 \\
Number of abnormal values in 75 g OGTT & 2.393 & $10.950(1.959-61.218)$ & 0.006 \\
\hline
\end{tabular}

AIT, antenatal insulin treatment; PG, plasma glucose; and $75 \mathrm{~g}$ OGTT, $75 \mathrm{~g}$ oral glucose tolerance test. 
TABLE 4: The cut-off values of 1-h and 2-h plasma glucose levels and the number of abnormal values to predict antenatal insulin treatment (AIT).

\begin{tabular}{|c|c|c|c|c|}
\hline & Cut-off point & Sensitivity & Specificity & AUC \\
\hline Postprandial PG at 1-hr in $75 \mathrm{~g}$ OGTT & $10.25 \mathrm{mmol} / \mathrm{L}$ & $100 \%$ & $77.8 \%$ & 0.872 \\
\hline Postprandial PG at 2-hr in $75 \mathrm{~g}$ OGTT & $8.75 \mathrm{mmol} / \mathrm{L}$ & $70 \%$ & $70.4 \%$ & 0.756 \\
\hline Number of abnormal values in $75 \mathrm{~g}$ OGTT & 1.5 & $80 \%$ & $74.1 \%$ & 0.783 \\
\hline
\end{tabular}

AUC, area under the curve; PG, plasma glucose; and $75 \mathrm{~g}$ OGTT, $75 \mathrm{~g}$ oral glucose tolerance test.

TABLE 5: Obstetrical outcomes.

\begin{tabular}{lccc}
\hline & AIT group $(n=10)$ & Diet group $(n=27)$ & $P$ values \\
\hline Gestational age at delivery (week) & $36.4 \pm 2.0$ & $38.2 \pm 2.4$ & $7.27 \pm 3.93$ \\
Maternal weight gain (kg) & $6.24 \pm 5.46$ & $5(18.5)$ & $0.046^{\dagger}$ \\
Preterm delivery, $n(\%)$ & $3(30.0)$ & $10(37.0)$ & $0.531^{\dagger}$ \\
Cesarean section, $n(\%)$ & $7(70.0)$ & $2(7.4)$ & $0.071^{\ddagger}$ \\
PIH, $n(\%)$ & $3(30.0)$ & $0.074^{\ddagger}$ \\
\hline
\end{tabular}

Data are shown as mean \pm standard deviation $(\mathrm{SD})$ or number $(n)$. AIT, antenatal insulin; PIH, pregnancy-induced hypertension; ${ }^{\dagger}$ Student's $t$-test; and ${ }^{\ddagger} \chi$ square test.

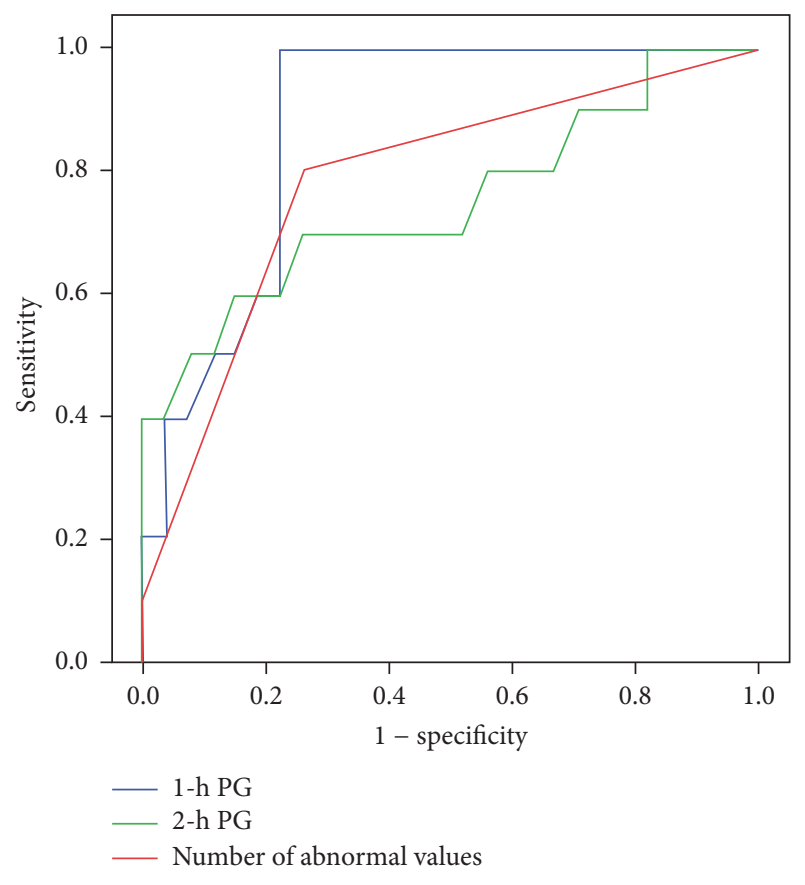

FIgURE 1

plasma glucose levels, and the rate of hypoglycemia were similar in both groups (Table 6).

\section{Discussion}

The main finding in the current investigation is that $1-\mathrm{h}$ and 2-h plasma glucose levels and the number of abnormal values in $75 \mathrm{~g}$ OGTT predict the requirement for AIT in GDM patients. The number of abnormal OGTT values was 1.5; therefore two or three of abnormal values in $75 \mathrm{~g}$ OGTT are a predictor for need of AIT with sensitivity of $90 \%$ and specificity $35.5 \%$. Ikenoue et al. evaluated the insulin sensitivity, insulin secretion, and $\beta$ cell function with insulin secretion-sensitivity index-2 (ISSI-2) in women between one and two or three abnormal OGTT values. The insulin sensitivity of women with two or three abnormal values deteriorated significantly compared with one abnormal value, although the insulin secretions were similar between two groups. Consequently, ISSI-2 levels of women with two or three abnormal values were significantly lower compared to one abnormal value. They also found that women with two or three abnormal OGTT values required more frequently AIT compared to one abnormal value [13]. Saisho et al. found that Japanese women with GDM failed to increase insulin secretion to compensate decreased insulin sensitivity compared to women with normal glucose tolerance [14]. Therefore, the number of abnormal OGTT values might reflect insulin sensitivity and $\beta$ cell function of women with GDM.

Previous studies reported diverse possible factors predicting the need for AIT including HbAlc, plasma glucose levels in OGTT, pregestational BMI, maternal age, gestational age at diagnosis, and family history of diabetes [7-11], but they were not associated with the requirement for AIT in the current study. The differences in risk factors among the previous and current studies may be derived from the clinical characteristics of the participants. For example, several studies showed that fasting glucose level could be predictor for AIT among women with GDM [7, 9-11, 15]. The mean of pregestational BMI among women who required AIT was reported as $31.6 \mathrm{~kg} / \mathrm{m}^{2}$ [11] and $29.9 \mathrm{~kg} / \mathrm{m}^{2}$ [7]. The proportion of overweight and obese women in AIT group was 72.9 percent [7]. In the current study, the mean of pregestational BMI among women who required AIT was $24.5 \mathrm{~kg} / \mathrm{m}^{2}$. The proportion of overweight and obese women in AIT group was 40 percent; the current study included overweight and obese woman, but prevalence was less compared to the previous studies. Black et al. found the association between BMI and fasting glucose levels, and obese women with GDM had significantly higher mean fasting glucose levels compared to 
TABLE 6: Neonatal characteristics.

\begin{tabular}{lccc}
\hline & AIT group $(n=10)$ & Diet group $(n=27)$ & $P$ values \\
\hline Birth weight (g) & $2703.2 \pm 526.0$ & $2827.6 \pm 534.3$ & $0.532^{\dagger}$ \\
Neonatal plasma glucose level (mmol/L) & $2.3 \pm 1.3$ & $3.0 \pm 1.0$ & $0.099^{\dagger}$ \\
Hypoglycemia, $n$ (\%) & $4(40)$ & $5(18.5)$ & $0.176^{\ddagger}$ \\
TTN, $n(\%)$ & $3(30.0)$ & $2(7.4)$ & $0.074^{\ddagger}$ \\
RDS, $n(\%)$ & $2(20.0)$ & $1(3.7)$ & $0.107^{\ddagger}$ \\
\hline
\end{tabular}

Data are shown as mean \pm standard deviation (SD) or number $(n)$. AIT, antenatal insulin; TTN, transient tachypnea of the newborn; RDS, respiratory distress syndrome; ${ }^{\dagger}$ Student's $t$-test; and ${ }^{\ddagger} \chi$-square test.

TABLE 7

\begin{tabular}{|c|c|c|c|}
\hline \multicolumn{4}{|c|}{ AIT group $(n=10)$} \\
\hline & $\begin{array}{c}\text { Pregestational } \mathrm{BMI}<25.0\left(\mathrm{~kg} / \mathrm{m}^{2}\right) \\
(n=6)\end{array}$ & $\begin{array}{c}\text { Pregestational } \mathrm{BMI} \geq 25.0\left(\mathrm{~kg} / \mathrm{m}^{2}\right) \\
(n=4)\end{array}$ & $P$ value \\
\hline \multirow[t]{3}{*}{$\begin{array}{l}\text { Fasting plasma glucose level } \\
(\mathrm{mmol} / \mathrm{L})^{9}\end{array}$} & $4.6 \pm 0.4$ & $5.2 \pm 0.5$ & $0.071^{\dagger}$ \\
\hline & \multicolumn{2}{|c|}{ Diet group $(n=27)$} & \\
\hline & $\begin{array}{c}\text { Pregestational } \mathrm{BMI}<25.0\left(\mathrm{~kg} / \mathrm{m}^{2}\right) \\
(n=20)\end{array}$ & $\begin{array}{c}\text { Pregestational } \mathrm{BMI} \geq 25.0\left(\mathrm{~kg} / \mathrm{m}^{2}\right) \\
(n=7)\end{array}$ & $P$ value \\
\hline $\begin{array}{l}\text { Fasting plasma glucose level } \\
(\mathrm{mmol} / \mathrm{L})^{9}\end{array}$ & $4.6 \pm 0.4$ & $5.0 \pm 0.4$ & $0.031^{\dagger}$ \\
\hline
\end{tabular}

AIT, antenatal insulin treatment; BMI, body mass index.

Data are shown as mean \pm SD.

${ }^{\dagger}$ By Student's $t$-test.

'At the time of the $75 \mathrm{~g}$ oral glucose-tolerance test.

overweight and normal weight women with GDM [16]. In the current study, indeed fasting glucose levels were significantly different between overweight or obese and normal weight women in Diet group, but fasting glucose levels were not significantly different between overweight, obese women and normal weight women in AIT group (Table 7). In the current study, the proportion of overweight and obese women of participants was less and fasting glucose level was not important risk factor for AIT.

$\beta$-Adrenergic agonist (ritodrine) infusion has been used as tocolytic; however it has some maternal side effects such as hyperglycemia. Even in nondiabetic pregnancy in women with normal glucose tolerance, it raised blood glucose levels additional $2.2 \mathrm{mmol} / \mathrm{L}(40 \mathrm{mg} / \mathrm{dl})$ [17] and the continuous ritodrine infusion increased plasma glucose levels during first 24 hours after beginning of ritodrine [18]. In contrast, the Canadian preterm labor investigators group reported that the incidences of hyperglycemia were similar between ritodrine and placebo infusion group [19]. In the current study there were four women to treat preterm labor with ritodrine in each group (Table 1), and there was one woman with twin in Diet group, as well as two women with twin in AIT group. Twin was risk factor of preterm labor [20]. In the current study, all three women with twin had treatment of preterm labor with ritodrine (Table 1). That was one of the reasons that AIT group had higher frequency of ritodrine, although there were no significant differences in the number of the women given ritodrine to arrest preterm delivery between AIT and Diet group.

There are some limitations in the current study. First, the number of participants was small to assess the predictors of requirement for AIT and it underestimated other important factors. Second, current study was single-center retrospective investigation. The prospective cohort study in larger participants is needed to further determine risk factors to predict AIT.

In conclusion, 1-h and 2-h plasma glucose levels and number of abnormal values in $75 \mathrm{~g}$ OGTT are useful parameters in predicting the requirement for AIT in GDM. Both maternal and neonatal complications are comparable in GDM patients with and without insulin therapy.

\section{Competing Interests}

The authors declare that they have no conflict of interests.

\section{Authors' Contributions}

Mayu Watanabe, Akihiro Katayama, Daisuke Ogawa, and Jun Wada contributed to the conception and design of current clinical study. Hidetoshi Kagawa, Daisuke Ogawa, and Jun Wada contributed to the acquisition, analysis, and interpretation of data. Mayu Watanabe and Jun Wada drafted the manuscript and Akihiro Katayama, Hidetoshi Kagawa, and Daisuke Ogawa critically revised the manuscript. All authors approved and agreed to be accountable for all aspects of the work.

\section{Acknowledgments}

Jun Wada receives speaker honoraria from Astellas, Boehringer Ingelheim, Novartis, and Tanabe Mitsubishi and 
receives grant support from Astellas, Bayer, Chugai, Daiichi Sankyo, Kissei, Kyowa Hakko Kirin, MSD, Otsuka, Teijin, Torii, Pfizer, Takeda, and Taisho Toyama.

\section{References}

[1] International Association of Diabetes and Pregnancy Study Groups Consensus Panel, "International association of diabetes and pregnancy study groups recommendations on the diagnosis and classification of hyperglycemia in pregnancy," Diabetes Care, vol. 33, no. 3, pp. 676-682, 2010.

[2] The Committee of the Japan Diabetes Society on the Diagnostic Criteria of Diabetes Mellitus, Y. Seino, K. Nanjo et al., "Report of the committee on the classification and diagnostic criteria of diabetes mellitus," Journal of Diabetes Investigation, vol. 1, no. 5, pp. 212-228, 2010.

[3] E. A. Garrison and S. Jagasia, "Inpatient management of women with gestational and pregestational diabetes in pregnancy," Current Diabetes Reports, vol. 14, no. 2, p. 457, 2014.

[4] M. B. Landon, C. Y. Spong, E. Thom et al., "A multicenter, randomized trial of treatment for mild gestational diabetes," The New England Journal of Medicine, vol. 361, no. 14, pp. 1339-1348, 2009.

[5] O. Langer, D. A. Rodriguez, E. M. Xenakis, M. B. McFarland, M. D. Berkus, and F. Arrendondo, "Intensified versus conventional management of gestational diabetes," American Journal of Obstetrics \& Gynecology, vol. 170, no. 4, pp. 1036-1047, 1994.

[6] C. A. Crowther, J. E. Hiller, J. R. Moss, A. J. McPhee, W. S. Jeffries, and J. S. Robinson, "Effect of treatment of gestational diabetes mellitus on pregnancy outcomes," The New England Journal of Medicine, vol. 352, no. 24, pp. 2477-2486, 2005.

[7] V. W. Wong and B. Jalaludin, "Gestational diabetes mellitus: who requires insulin therapy?" Australian and New Zealand Journal of Obstetrics and Gynaecology, vol. 51, no. 5, pp. 432436, 2011.

[8] A. D. Sapienza, R. P. V. Francisco, T. C. Trindade, and M. Zugaib, "Factors predicting the need for insulin therapy in patients with gestational diabetes mellitus," Diabetes Research and Clinical Practice, vol. 88, no. 1, pp. 81-86, 2010.

[9] T. Pertot, L. Molyneaux, K. Tan, G. P. Ross, D. K. Yue, and J. Wong, "Can common clinical parameters be used to identify patients who will need insulin treatment in gestational diabetes mellitus?” Diabetes Care, vol. 34, no. 10, pp. 2214-2216, 2011.

[10] S. Meshel, E. Schejter, T. Harel et al., "Can we predict the need for pharmacological treatment according to demographic and clinical characteristics in gestational diabetes?" The Journal of Maternal-Fetal \& Neonatal Medicine, vol. 29, no. 13, pp. 20622066, 2016.

[11] O. Bakiner, "Risk factors that can predict antenatal insulin need in gestational diabetes," Journal of Clinical Medicine Research, vol. 5, no. 5, pp. 381-388, 2013.

[12] K. Baptiste-Roberts, B. B. Barone, T. L. Gary et al., "Risk Factors for type 2 diabetes among women with gestational diabetes: a systematic review," American Journal of Medicine, vol. 122, no. 3, pp. 207.e4-214.e4, 2009.

[13] S. Ikenoue, K. Miyakoshi, Y. Saisho et al., "Clinical impact of women with gestational diabetes mellitus by the new consensus criteria: two year experience in a single institution in Japan," Endocrine Journal, vol. 61, no. 4, pp. 353-358, 2014.

[14] Y. Saisho, K. Miyakoshi, M. Tanaka et al., "Beta cell dysfunction and its clinical significance in gestational diabetes," Endocrine Journal, vol. 57, no. 11, pp. 973-980, 2010.
[15] B. Akinci, A. Celtik, S. Yener, and S. Yesil, "Is fasting glucose level during oral glucose tolerance test an indicator of the insulin need in gestational diabetes?" Diabetes Research and Clinical Practice, vol. 82, no. 2, pp. 219-225, 2008.

[16] M. H. Black, D. A. Sacks, A. H. Xiang, and J. M. Lawrence, “The relative contribution of prepregnancy overweight and obesity, gestational weight gain, and IADPSG-defined gestational diabetes mellitus to fetal overgrowth," Diabetes Care, vol. 36, no. 1, pp. 56-62, 2013.

[17] M. Ogawa, Y. Matsuda, A. Kobayashi et al., "Ritodrine should be carefully administered during antenatal glucocorticoid therapy even in nondiabetic pregnancies," ISRN Obstetrics and Gynecology, vol. 2013, Article ID 120735, 4 pages, 2013.

[18] M. Hirai, I. Yasuhi, T. Ishimaru, T. Yamabe, and K. Kubota, "Effect of prolonged intravenous ritodrine tocolysis on diurnal glucose profiles in pregnant women with normal carbohydrate tolerance," Nihon Sanka Fujinka Gakkai Zasshi, vol. 48, no. 7, pp. 488-494, 1996.

[19] The Canadian Preterm Labor Investigators Group, "Treatment of preterm labor with the beta-adrenergic agonist ritodrine," The New England Journal of Medicine, vol. 327, no. 5, pp. 308312, 1992.

[20] H. Minakami and I. Sato, "Reestimating date of delivery in multifetal pregnancies," The Journal of the American Medical Association, vol. 275, no. 18, pp. 1432-1434, 1996. 


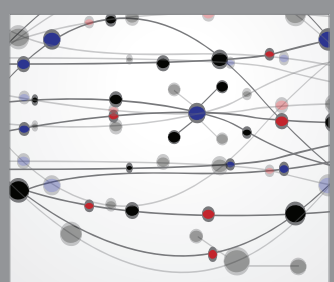

The Scientific World Journal
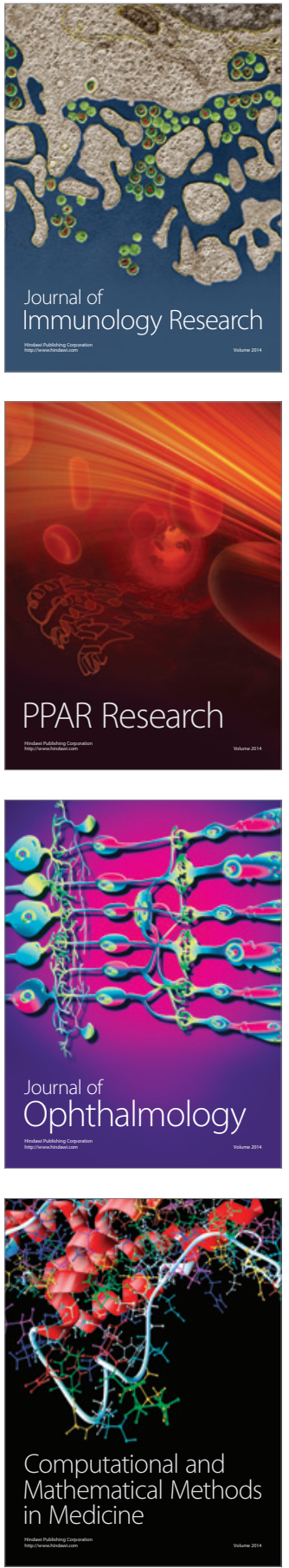

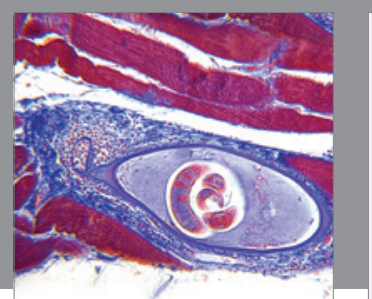

Gastroenterology Research and Practice

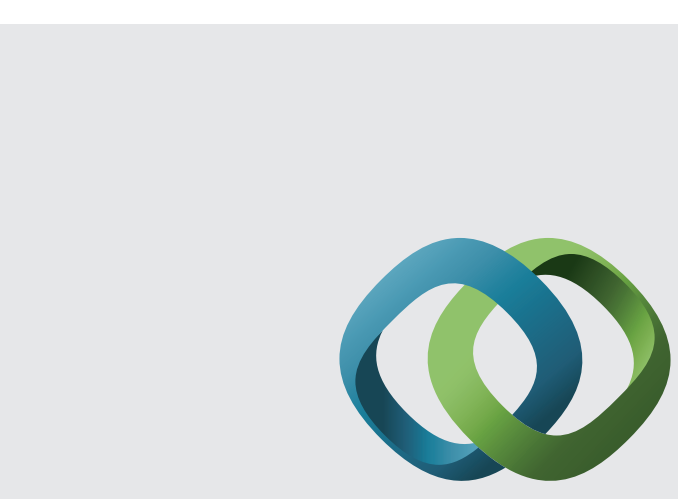

\section{Hindawi}

Submit your manuscripts at

http://www.hindawi.com
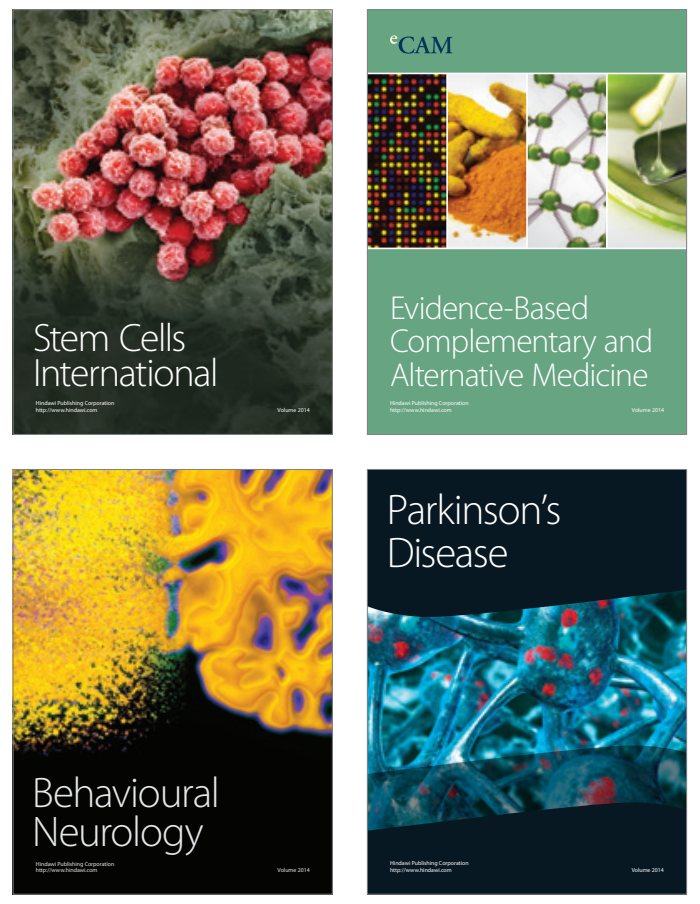
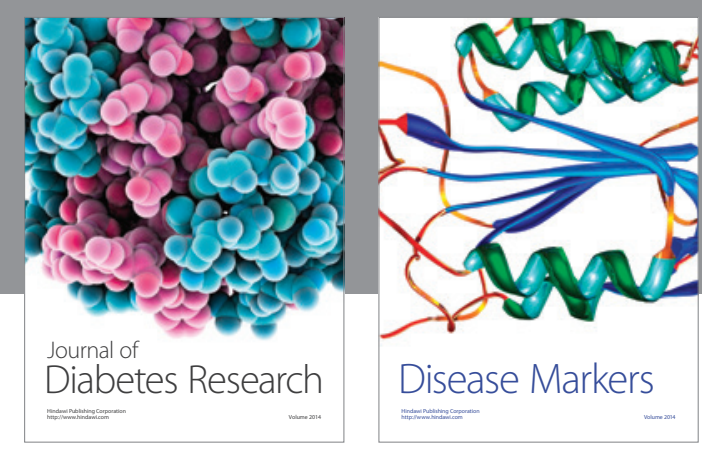

Disease Markers
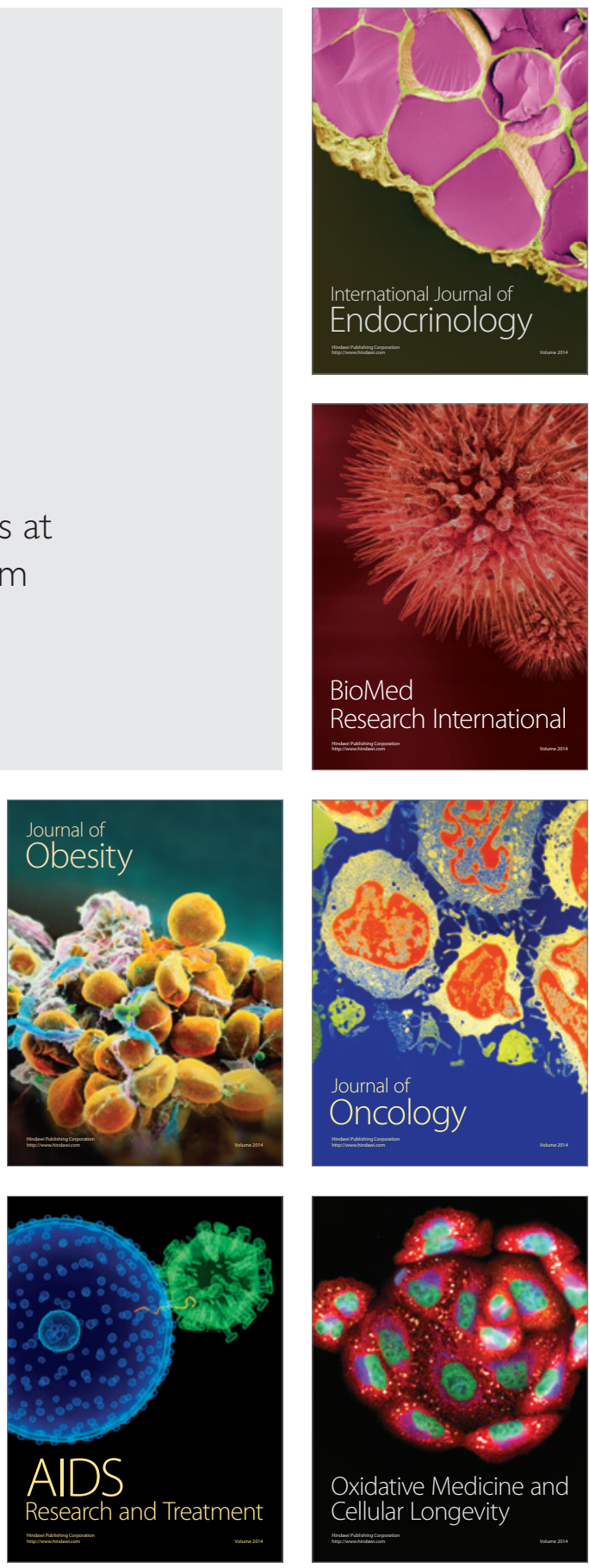